Article

\title{
A New Preoperative Scoring System for Predicting Aggressiveness of Non-Functioning Pancreatic Neuroendocrine Neoplasms
}

\author{
Tetsuya Takikawa $^{1}{ }^{1}$, Kazuhiro Kikuta ${ }^{1}$, Shin Hamada ${ }^{1}$, Kiyoshi Kume ${ }^{1}$, Shin Miura ${ }^{1}$ D , Naoki Yoshida ${ }^{1}$, \\ Yu Tanaka ${ }^{1}$, Ryotaro Matsumoto ${ }^{1}$, Mio Ikeda ${ }^{1}$, Fumiya Kataoka ${ }^{1}$ (D), Akira Sasaki ${ }^{1}$, Hidehiro Hayashi ${ }^{1}$, \\ Waku Hatta ${ }^{1}$, Yohei Ogata ${ }^{1} \mathbb{D}$, Kei Nakagawa ${ }^{2} \mathbb{D}$, Michiaki Unno $^{2}$ and Atsushi Masamune ${ }^{1, * \mathbb{D}}$
}

1 Division of Gastroenterology, Tohoku University Graduate School of Medicine, Sendai 980-8574, Japan; t-takikawa@med.tohoku.ac.jp (T.T.); kkikuta@med.tohoku.ac.jp (K.K.); hamadas@med.tohoku.ac.jp (S.H.); kkume@med.tohoku.ac.jp (K.K.); miurashin@med.tohoku.ac.jp (S.M.); iiiiiiiiiiiiii14@hotmail.com (N.Y.); 1055@gmail.com (Y.T.); rmat44@gmail.com (R.M.); mio-0311@watch.ocn.ne.jp (M.I.); a9mb1039@yahoo.co.jp (F.K.); akira.ss.0911@gmail.com (A.S.); hayashisaporo@gmail.com (H.H.); waku-style@festa.ocn.ne.jp (W.H.); gmaps177@gmail.com (Y.O.)

2 Department of Surgery, Graduate School of Medicine, Tohoku University, Sendai 980-8574, Japan; kein@surg.med.tohoku.ac.jp (K.N.); m_unno@surg.med.tohoku.ac.jp (M.U.)

* Correspondence: amasamune@med.tohoku.ac.jp; Tel.:+81-22-717-7171; Fax: +81-22-717-7177

Citation: Takikawa, T.; Kikuta, K. Hamada, S.; Kume, K.; Miura, S.; Yoshida, N.; Tanaka, Y.; Matsumoto, R.; Ikeda, M.; Kataoka, F. et al. A New Preoperative Scoring System for Predicting Aggressiveness of Non-Functioning Pancreatic Neuroendocrine Neoplasms. Diagnostics 2022, 12, 397. https:/ / doi.org/10.3390/diagnostics12020397

Academic Editor: Susumu Hijioka

Received: 30 December 2021

Accepted: 1 February 2022

Published: 3 February 2022

Publisher's Note: MDPI stays neutral with regard to jurisdictional claims in published maps and institutional affiliations.

Copyright: (C) 2022 by the authors. Licensee MDPI, Basel, Switzerland. This article is an open access article distributed under the terms and conditions of the Creative Commons Attribution (CC BY) license (https:// creativecommons.org/licenses/by/ $4.0 /)$

\begin{abstract}
The management of non-functioning pancreatic neuroendocrine neoplasms (NF-PanNENs) is still controversial. This study aimed to develop a new scoring system for treatment decisions at initial diagnosis based on the identification of the predictive factors for aggressive NF-PanNENs. Seventy-seven patients who had been pathologically diagnosed with NF-PanNENs were enrolled. We retrospectively reviewed 13 variables that could be assessed preoperatively. Univariate and multivariate stepwise logistic regression analyses were performed to identify factors for the aggressiveness of NF-PanNENs, and a scoring system was developed by assigning weighted points proportional to their $\beta$ regression coefficient. Tumor size $>20 \mathrm{~mm}$ on contrast-enhanced computed tomography, tumor non-vascularity, and Ki-67 labeling index $\geq 5 \%$ on endoscopic ultrasound-guided fine-needle aspiration specimens were identified as independent factors for predicting the aggressiveness of NF-PanNENs. The new scoring system, developed using the identified factors, had an excellent discrimination ability, with area under the curve of 0.92 (95\% CI, 0.85-0.99), and good calibration ( $p=0.72$, Hosmer-Lemeshow test). Ten-year overall survival rates in low-risk ( 0 point), intermediaterisk (1 to 2 points), and high-risk ( 3 to 4 points) groups were $100 \%, 90.9 \%$, and $24.3 \%$, respectively. This new scoring system would be useful for treatment decisions and prognostic prediction at initial diagnosis.
\end{abstract}

Keywords: endoscopic ultrasound-guided fine-needle aspiration; pancreatic cancer; pancreatic neuroendocrine neoplasm; prediction model; Ki-67

\section{Introduction}

Pancreatic neuroendocrine neoplasms (PanNENs) are rare pancreatic tumors, accounting for $1-2 \%$ of all pancreatic tumors [1-3]. The number of PanNENs cases is steadily increasing [4-6]. The Surveillance, Epidemiology, and End Results (SEER) database revealed that the annual incidence of patients with PanNENs in the USA were 0.27 per 100,000 in the period 1987-1996, 0.43 in 1997-2006, and 1.01 in 2007-2016 [3]. The incease is particularly evident in asymptomatic and small non-functioning PanNENs (NF-PanNENs) [4-6]. According to a population-based study based in the USA, the incidence of pancreatic neuroendocrine tumors (PanNETs) $\leq 2 \mathrm{~cm}$ increased by 710\% between 1988 and 2012 [4]. The proportion of the incidentally-detected cases increased from $19 \%$ of all NF-PanNENs cases in the period 2010-2011 to 57\% in 2019-2020 [6]. These increases are likely to be 
attributable to the advances in imaging modalities, including endoscopic ultrasonography (EUS) [4,7]. EUS-guided fine-needle aspiration (EUS-FNA) has a high ability for histological diagnosis of PanNENs [7]. PanNENs were found in $0.8-10 \%$ of all autopsied cases [8,9], suggesting that the actual prevalence rates might be higher than those previously reported. Therefore, it is likely that the number of cases with PanNENs, particularly incidental and asymptomatic small lesions, might be further increased, and be of a more important clinical issue in the future.

Management of NF-PanNENs is still controversial. Tumor size is considered to be correlated with the aggressiveness of PanNENs [10-12], and recent studies have indicated that conservative management of small NF-PanNENs may be a good option based on their favorable prognosis [10,13-15]. The latest European Neuroendocrine Tumor Society (ENETS) guidelines proposed conservative management for NF-PanNENs with tumor size $\leq 20 \mathrm{~mm}$ in selected patients with significant comorbidity or advanced age [16]. The National Comprehensive Cancer Network (NCCN) guidelines for Neuroendocrine and Adrenal Tumors, version 4, 2021, proposed that observation can be considered for incidentally detected NF-PanNENs with tumor size $\leq 20 \mathrm{~mm}$ [17]. On the other hand, several studies have advocated that surgery should be performed even for small lesions $\leq 20 \mathrm{~mm}$ based on the improved survival rates compared with the conservative management group $[4,18,19]$. Because NF-PanNENs are biologically heterogenous [16], it may be difficult to accurately evaluate the aggressiveness of NF-PanNENs and to determine a management strategy solely based on tumor size. Other predictive factors for survival or recurrence after surgery include pathological lymph node metastasis, vascular invasion, tumor grade, and surgical resection margin [11,20-23]. Based on these predictive factors, several clinically relevant scoring systems have been developed [24-27]. However, these factors can be evaluated only after surgery using the resected specimens, and the development of scoring systems for treatment decisions at the initial diagnosis of NF-PanNENs is urgently needed. The aim of this study was to identify predictive factors for the aggressiveness of NF-PanNENs, which can be evaluated before surgery, and to develop a new scoring system for treatment decisions at initial diagnosis.

\section{Materials and Methods}

\subsection{Study Design and Patients}

This study was a single-center, retrospective, observational study. We analyzed the patients with PanNENs diagnosed at Tohoku University Hospital between June 2008 and December 2020. Inclusion criteria were as follows: (1) patients with pathologically diagnosed PanNENs by surgical or EUS-FNA specimens; and (2) patients who had undergone preoperative EUS-FNA and multiphase contrast-enhanced computed tomography (CE-CT) at initial diagnosis. Exclusion criteria were as follows: (1) functioning PanNENs; (2) hereditary diseases such as multiple endocrine neoplasia type 1 (MEN-1) and von Hippel-Lindau (VHL) diseases; (3) presence of synchronous malignancies; (4) insufficient EUS-FNA sample for pathological evaluation; (5) undetectable tumors on CE-CT; and (6) less than 6 months of follow-up period.

\subsection{Data Collection and Candidate Variables}

Clinical, imaging, and pathological data were collected from medical records. We reviewed age, sex, and presence of symptoms as clinical variables. We selected additional candidate variables based on the previous studies showing their utilities for the prediction of aggressive PanNENs. We evaluated the tumor size, tumor location, number of tumors, tumor vascularity, cystic degeneration/necrosis, calcification, and main pancreatic duct (MPD) and common bile duct (CBD) involvement on CE-CT [28-32]. Abnormal uptake on ${ }^{18}$ F-fluorodeoxyglucose $\left({ }^{18} \mathrm{~F}-\mathrm{FDG}\right)$ positron emission tomography (PET)/CT was also assessed, because its utility to predict prognosis and tumor grade has been reported in patients with PanNENs [33]. We included Ki-67 labeling index (LI) on EUS-FNA specimens as another candidate variable [34,35]. Regarding its threshold, the World Health Organi- 
zation (WHO) classification define $\mathrm{Ki}-67 \mathrm{LI} \geq 3 \%$ as the threshold for tumor grading [36], but recent studies have reported that $\mathrm{Ki}-67 \mathrm{LI} \geq 5 \%$ was a good threshold of aggressiveness $[37,38]$. Therefore, we analyzed Ki-67 LI of both $3 \%$ and $5 \%$ on EUS-FNA specimens as pathological variables. We did not include ${ }^{68} \mathrm{Ga}$-DOTA-Tyr ${ }^{3}$-octreotide PET because it is not covered by medical insurance in Japan and no patients underwent the examination.

\subsection{Definitions}

NF tumors were defined as tumors with no symptoms of hormonal excess regardless of the laboratory data. We determined the tumor grade according to the WHO 2017 classification [36] based on Ki-67 LI and mitotic count using surgical specimens in resected cases and on Ki-67 LI using EUS-FNA specimens in non-resected cases. We used the ENETS TNM staging system [39] for disease stage classification. We defined aggressive NF-PanNENs as disease-related death, recurrence after surgery, pathological and imaging lymph node metastases, and distant metastases at initial diagnosis according to the previous reports with some modifications [40,41].

Tumor size was defined as the largest diameter measured on CE-CT at initial diagnosis. To evaluate the vascularity, we measured the Hounsfield units (HU) value by placing the oval region of interest (ROI) of $10 \mathrm{~mm}^{2}$ within the tumor in arterial phase on CE-CT, avoiding areas of calcification, cystic degeneration/necrosis, and pancreatic duct [32,42]. Hypervascular tumor was defined as if the $\mathrm{HU}$ value in the arterial phase within the tumor was at least $10 \mathrm{HU}$ higher than that of the surrounding normal pancreatic parenchyma [32]. Cystic degeneration/necrosis was defined as non-enhanced areas of circular or ovoid shape, and the calcification within the tumor was assessed on plain CT image [42]. MPD involvement was defined as interruption of the MPD with upstream dilatation $(\geq 3 \mathrm{~mm})[29,30]$. CBD involvement was defined as interruption of the CBD with upstream dilatation $(\geq 10 \mathrm{~mm}$ ) or symptoms of jaundice [30]. Imaging lymph node metastases were diagnosed when there was a diameter $\geq 10 \mathrm{~mm}$ with irregular margins or heterogeneous enhancement, when there was an abnormal uptake on somatostatin receptor scintigraphy (SRS) [28].

Significant progression was defined as a greater than $5 \mathrm{~mm}$ or $20 \%$ increase in total in the size of the primary tumor from the baseline [43]. Overall survival (OS) was defined as the time from pathological diagnosis to the date of the last follow-up or death due to any cause. The definition of disease-free survival (DFS) was the period from surgical resection to radiological evidence of local recurrence, distant metastasis, or death due to any cause.

\subsection{Statistical Analysis}

Continuous variables were presented as mean (standard deviation (SD)) or median (interquartile range (IQR)), and categorical variables were expressed as numbers (percentages). For comparison between two groups, Student's t-test or Wilcoxon rank sum test was used for continuous variables, and the chi-square test or Fisher's exact test was used for categorical variables. Survival curves were estimated using the Kaplan-Meier method and compared using the Log-rank test.

For development of a scoring system, we performed a univariate and multivariate stepwise logistic regression analyses. Candidate variables with a difference of $p<0.2$ in univariate analysis were entered into forward stepwise selection based on Akaike's Information Criterion (AIC), and selected variables were analyzed by multivariate analysis. We allocated points proportional to $\beta$ regression coefficient values for the predictive variables determined in the multivariate analysis as previously reported [44,45]. The coefficient of each variable was divided by the lowest $\beta$ value among variables included into the final prediction model and rounded to the nearest integer. The adjustment of each coefficient is a standard method for driving a scoring system [46]. The total score in each patient was then calculated. The model's discrimination was assessed by the area under the curve (AUC) in the receiver operating characteristic curve, and its calibration was evaluated by the Hosmer-Lemeshow test. Internal validation was estimated using the bootstrap 
resampling with 1000 repetitions. The Cochran-Armitage test was used to analyze trends in risk groups according to the scoring system. The AUC values were compared using the DeLong test [47].

JMP Pro 16 (SAS Institute Inc., Cary, NC, USA), IBM SPSS Statistics 21 (IBM Corp., Armonk, NY, USA), and R version 3.6.1 for Windows software (R Foundation) were used for statistical analysis, and a two-sided $p$-value $<0.05$ was considered statistically significant.

\section{Results}

\subsection{Characeteristics of the Enrolled Patients}

Figure 1 shows the flowchart of patient enrollment. During the study period, 147 patients met the inclusion criteria. The following patients were excluded: those with functioning PanNENs $(n=42)$, hereditary diseases such as MEN-1 $(n=5)$ and VHL $(n=2)$, synchronous other malignancies $(n=10)$, insufficient EUS-FNA sample for pathological evaluation $(n=2)$, undetectable lesions on CE-CT $(n=3)$, less than 6 months of follow-up period $(n=6)$. Finally, 77 patients with NF-PanNENs were enrolled, and their clinicopathological characteristics are shown in Table 1. The mean patient age (SD) was 61.1 (12.9) years, and $38(49.4 \%)$ patients were male. The median tumor size (IQR) at initial diagnosis was 18 (12-34) $\mathrm{mm}$. Lymph node and distant metastases occurred in 19 patients (24.7\%) and 16 patients (20.8\%), respectively. The tumor grades, based on the WHO 2017 classification, were G1 for 38 patients (49.4\%), G2 for 26 (33.8\%), NET G3 for $3(3.9 \%)$, and neuroendocrine carcinoma (NEC) G3 for 10 (13.0\%). Fifty-four patients $(70.1 \%)$ underwent surgical resection immediately after the diagnosis, 14 (18.2\%) received chemotherapy, and $8(10.4 \%)$ underwent follow-up surveillance. The median follow-up period (IQR) was 1636 (568-3024) days. Five-year and ten-year OS rates were $85.9 \%$ and $76.3 \%$, respectively. For the 8 patients who underwent follow-up surveillance, the mean patient age (SD) was 70.5 (9.0) years, and $7(87.5 \%)$ were female. The median tumor size (IQR) at initial diagnosis was $9(7-13) \mathrm{mm}$. Significant progression was not observed in any of these 8 patients during the median observation period of 1621 days.

\section{7 patients were pathologically diagnosed with PanNENs between June 2008 and December}

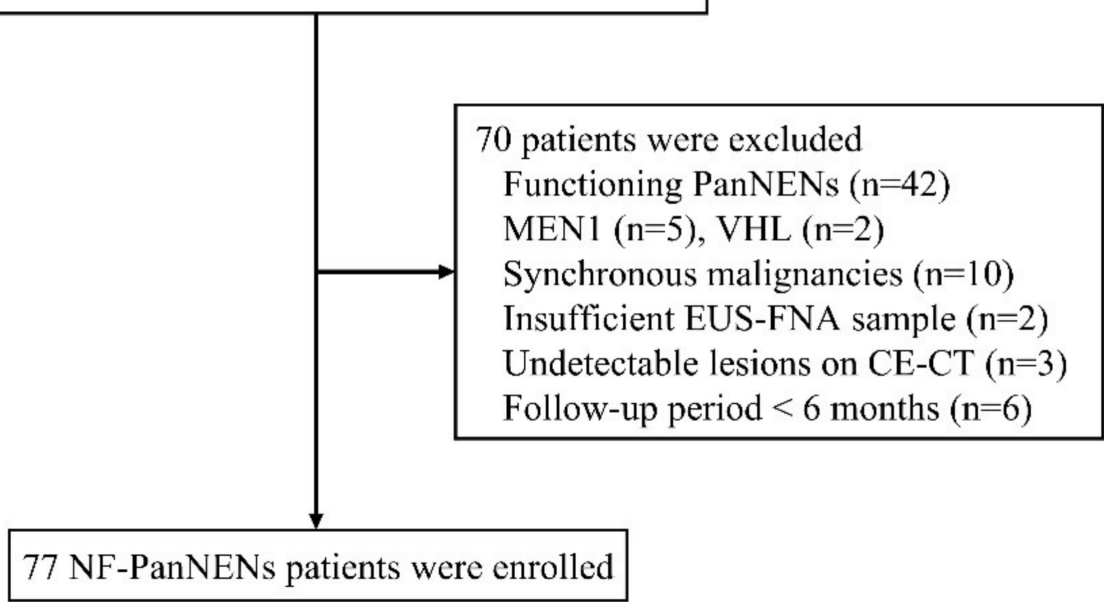

Figure 1. Flowchart of patient enrollment. 
Table 1. Clinicopathological characteristics of patients with NF-PanNENs.

\begin{tabular}{|c|c|}
\hline Variables & NF-PanNENs $(n=77)$ \\
\hline Age, mean (SD), years & $61.1(12.9)$ \\
\hline Sex, male, $n(\%)$ & $38(49.4)$ \\
\hline Median tumor size, mm (IQR) & $18(12-34)$ \\
\hline Symptoms, yes, $n$ (\%) & $26(33.8)$ \\
\hline $\begin{array}{l}\text { Tumor location, } n(\%) \\
\text { Head } \\
\text { Body/Tail } \\
\text { Multiple }\end{array}$ & $\begin{array}{c}30(39.0) \\
44(57.1) \\
3(3.9)\end{array}$ \\
\hline Lymph node metastasis, $n(\%)$ & $19(24.7)$ \\
\hline Distant metastasis, $n(\%)$ & $16(20.8)$ \\
\hline $\begin{array}{l}\text { Tumor grade (WHO 2017), } n(\%) \\
\text { G1 } \\
\text { G2 } \\
\text { NET G3 } \\
\text { NEC G3 }\end{array}$ & $\begin{array}{c}38(49.4) \\
26(33.8) \\
3(3.9) \\
10(13.0)\end{array}$ \\
\hline $\begin{array}{l}\text { ENETS Stage, } n(\%) \\
\text { I } \\
\text { II } \\
\text { III } \\
\text { IV }\end{array}$ & $\begin{array}{l}42(54.5) \\
11(14.3) \\
8(10.4) \\
16(20.8)\end{array}$ \\
\hline $\begin{array}{l}\text { Treatment, } n(\%) \\
\text { Surgery } \\
\text { Chemotherapy } \\
\text { Surveillance } \\
\text { Best supportive care }\end{array}$ & $\begin{array}{l}54(70.1) \\
14(18.2) \\
8(10.4) \\
1(1.3)\end{array}$ \\
\hline $\begin{array}{l}\text { Overall survival rate }(\%) \\
\text { 5-year OS rate } \\
\text { 10-year OS rate }\end{array}$ & $\begin{array}{l}85.9 \\
76.3\end{array}$ \\
\hline Median follow-up period, days (IQR) & $1636(568-3024)$ \\
\hline
\end{tabular}

Of the 77 patients, $46(59.7 \%)$ were classified into the non-aggressive group and $31(40.3 \%)$ were classified into the aggressive group. Table 2 shows the comparison of baseline characteristics between the two groups. There were significant differences in tumor size $(p<0.001)$, tumor grade $(p<0.001)$, disease stage $(p<0.001)$, treatment $(p<0.001)$, and prognosis $(p<0.001)$ between the two groups. There were 50 patients whose tumor size was $\leq 20 \mathrm{~mm}$. Among them, $9(18 \%)$ patients were classified into the aggressive group due to lymph node metastasis $(n=3)$, distant metastasis $(n=2)$, postoperative recurrence $(n=3)$, or disease-related death due to distant metastasis $(n=1)$. In the non-aggressive group, G1 tumors accounted for $76.1 \%$, and no G3 tumors were observed. As for the ENETS stage, $87.0 \%$ of the patients in the non-aggressive group were Stage I, whereas approximately $80 \%$ in the aggressive group were Stage III or IV. The 5-year and 10-year OS rates were both $96.8 \%$ in the non-aggressive group, and $70.0 \%$ and $50.9 \%$ in the aggressive group, respectively. The median follow-up period in the non-aggressive and aggressive groups were 1655 and 1395 days, with no significant difference $(p=0.19)$. 
Table 2. Baseline characteristics between the non-aggressive and aggressive groups.

\begin{tabular}{|c|c|c|c|}
\hline Variables & $\begin{array}{l}\text { Non-Aggressive Group } \\
(n=46)\end{array}$ & $\begin{array}{c}\text { Aggressive Group } \\
\quad(n=31)\end{array}$ & $p$ Value \\
\hline Age, mean (SD), years & $63.3(11.5)$ & $57.9(14.3)$ & 0.07 \\
\hline Sex, male, $n(\%)$ & $22(47.8)$ & $16(51.6)$ & 0.74 \\
\hline Median tumor size, mm (IQR) & $14(9-18)$ & $38(20-53)$ & $<0.001$ \\
\hline Tumor grade (WHO 2017), $n(\%)$ & & & $<0.001$ \\
\hline G1 & $35(76.1)$ & $3(9.7)$ & \\
\hline G2 & 11 (23.9) & $15(48.4)$ & \\
\hline NET G3 & $0(0)$ & $3(9.7)$ & \\
\hline NEC G3 & $0(0)$ & $10(32.3)$ & \\
\hline ENETS Stage, $n(\%)$ & & & $<0.001$ \\
\hline I & $40(87.0)$ & $2(6.5)$ & \\
\hline II & $6(13.0)$ & $5(16.1)$ & \\
\hline III & $0(0)$ & $8(25.8)$ & \\
\hline IV & $0(0)$ & $16(51.6)$ & \\
\hline Treatment, $n(\%)$ & & & $<0.001$ \\
\hline Surgery & $37(80.4)$ & $17(54.8)$ & \\
\hline Chemotherapy & $1(2.2)$ & $13(41.9)$ & \\
\hline Surveillance & 8 (17.4) & $0(0)$ & \\
\hline Best supportive care & $0(0)$ & $1(3.2)$ & \\
\hline Prognosis, $(\%)$ & & & $<0.001$ \\
\hline 5-year OS rate & 96.8 & 70.0 & \\
\hline 10-year OS rate & 96.8 & 50.9 & \\
\hline $\begin{array}{l}\text { Median follow-up period, days } \\
\text { (IQR) }\end{array}$ & $1655(287-2824)$ & $1395(865-3055)$ & 0.19 \\
\hline
\end{tabular}

\subsection{Univariate and Multivariate Stepwise Logistic Regression Analyses of Candidate Variables}

We performed univariate logistic regression analysis to select candidate variables to predict the aggressiveness of NF-PanNENs, and age $(p=0.09)$, presence of symptoms $(p<0.001)$, tumor size $(p<0.001)$, tumor vascularity $(p<0.001)$, cystic degeneration/necrosis $(p=0.002)$, tumor calcification $(p=0.10)$, MPD or CBD involvement $(p=0.003)$, abnormal uptake on ${ }^{18}$ F-FDG PET/CT $(p=0.003)$, and EUS-FNA Ki-67 LI $\geq 3 \%(p<0.001)$ and $\geq 5 \%(p<0.001)$ revealed $p$ value of $<0.2$ (Table 3$)$. Among them, three variables (tumor size, tumor vascularity, and EUS-FNA Ki-67 LI $\geq 5 \%$ ) were selected by forward stepwise selection based on the Akaike's Information Criterion. Multivariate logistic regression analysis revealed that tumor size $>20 \mathrm{~mm}(p=0.004)$, tumor non-hypervascularity $(p=0.001)$, and EUS-FNA Ki-67 LI $\geq 5 \%(p=0.034)$ were independently associated with the aggressiveness of NF-PanNENs (Table 4).

\subsection{Development of a Scoring System}

We then developed a scoring system using the three identified factors based on their $\beta$ regression coefficient values. Because the lowest coefficient value was 1.94 for EUSFNA ki-67 LI, the $\beta$ regression coefficient values of each factor were divided by 1.94 and rounded to the nearest integer. As a result, tumor size $>20 \mathrm{~mm}$ was assigned as 1 point, tumor non-hypervascularity as 2 points, and EUS-FNA Ki-67 LI $\geq 5 \%$ as 1 point (Table 4). The discrimination ability of the model was excellent, with AUC of 0.92 (95\% confidence interval (CI), 0.85-0.99) with standard error (SE) of 0.04. Based on the cut-off level of 2 points, the positive and negative predictive values were $88.9 \%$ and $86.0 \%$, respectively. The Hosmer-Lemeshow test also indicated good calibration $(p=0.72)$. The model was internally validated using bootstrap resampling with 1000 repetitions, which showed mean AUC of 0.92 (95\% CI, 0.84-0.98) with SE of 0.001 . 
Table 3. Univariate analysis of candidate variables.

\begin{tabular}{|c|c|c|c|c|}
\hline Variables & $\begin{array}{l}\text { Non-Aggressive Group } \\
\qquad(n=46)\end{array}$ & $\begin{array}{c}\text { Aggressive Group } \\
\qquad(n=31)\end{array}$ & OR $(95 \% \mathrm{CI})$ & $p$ Value \\
\hline \multicolumn{5}{|l|}{ Age (years), $n(\%)$} \\
\hline$<65$ & $22(47.8)$ & $21(67.7)$ & 1 & \multirow{2}{*}{0.09} \\
\hline$\geq 65$ & $24(52.2)$ & $10(32.3)$ & $0.44(0.09-1.13)$ & \\
\hline \multicolumn{5}{|l|}{ Sex, $n(\%)$} \\
\hline Female & $24(52.2)$ & $15(48.4)$ & 1 & \multirow{2}{*}{0.74} \\
\hline Male & $22(47.8)$ & $16(51.6)$ & $1.16(0.47-2.90)$ & \\
\hline \multicolumn{5}{|l|}{ Symptoms, $n(\%)$} \\
\hline No & $40(87.0)$ & $11(35.5)$ & 1 & \multirow[t]{2}{*}{$<0.001$} \\
\hline Yes & $6(13.0)$ & $20(64.5)$ & $12.12(3.91-37.53)$ & \\
\hline \multicolumn{5}{|l|}{ Tumor location, $n(\%)$} \\
\hline Head & $16(34.8)$ & $14(45.2)$ & 1 & \multirow{3}{*}{0.65} \\
\hline Body/tail & $28(60.9)$ & $16(51.6)$ & $0.65(0.60-3.94)$ & \\
\hline Multiple & $2(4.3)$ & $1(3.2)$ & $0.57(0.05-7.00)$ & \\
\hline \multicolumn{5}{|c|}{ Number of tumors, $n(\%)$} \\
\hline Single & $44(95.7)$ & $30(96.8)$ & 1 & \multirow[t]{2}{*}{0.80} \\
\hline Multiple & $2(4.3)$ & $1(3.2)$ & $0.73(0.06-8.45)$ & \\
\hline \multicolumn{5}{|l|}{ Tumor size $(\mathrm{mm}), n(\%)$} \\
\hline$\leq 20$ & $41(89.1)$ & $9(29.0)$ & 1 & \multirow[t]{2}{*}{$<0.001$} \\
\hline$>20$ & $5(10.9)$ & $22(71.0)$ & $20.0(5.98-67.20)$ & \\
\hline \multicolumn{5}{|l|}{ Tumor vascularity, $n(\%)$} \\
\hline Hypervascular & $44(95.7)$ & $10(32.3)$ & 1 & \multirow[t]{2}{*}{$<0.001$} \\
\hline Non-hypervascular & $2(4.3)$ & $21(67.7)$ & $46.2(9.28-229.91)$ & \\
\hline \multicolumn{5}{|c|}{ Cystic degeneration/necrosis, $n(\%)$} \\
\hline No & $37(80.4)$ & $14(45.2)$ & 1 & \multirow[t]{2}{*}{0.002} \\
\hline Yes & $9(19.6)$ & $17(54.8)$ & $1.81(1.81-13.78)$ & \\
\hline \multicolumn{5}{|c|}{ Tumor calcification, $n(\%)$} \\
\hline No & $45(97.8)$ & $27(87.1)$ & 1 & \multirow[t]{2}{*}{0.10} \\
\hline Yes & $1(2.2)$ & $4(12.9)$ & $6.67(0.71-62.79)$ & \\
\hline \multicolumn{5}{|c|}{ MPD or CBD involvement, $n(\%)$} \\
\hline No & $43(93.5)$ & $20(64.5)$ & 1 & \multirow[t]{2}{*}{0.003} \\
\hline Yes & $3(6.5)$ & $11(35.5)$ & $7.88(1.98-31.41)$ & \\
\hline \multicolumn{5}{|c|}{${ }^{18}$ F-FDG PET $/ \mathrm{CT}^{\#}, n(\%)$} \\
\hline Negative & $23(54.8)$ & $5(17.9)$ & 1 & \multirow[t]{2}{*}{0.003} \\
\hline Positive & $19(45.2)$ & $23(82.1)$ & $5.57(1.78-17.45)$ & \\
\hline \multicolumn{5}{|c|}{ EUS-FNA Ki-67 LI $\geq 3 \%, n(\%)$} \\
\hline No & $38(82.6)$ & $9(29.0)$ & 1 & \multirow[t]{2}{*}{$<0.001$} \\
\hline Yes & $8(17.4)$ & $22(71.0)$ & $11.61(3.91-34.45)$ & \\
\hline \multicolumn{5}{|c|}{ EUS-FNA Ki-67 LI $\geq 5 \%, n(\%)$} \\
\hline No & $43(93.5)$ & $11(35.5)$ & 1 & \multirow[t]{2}{*}{$<0.001$} \\
\hline Yes & $3(6.5)$ & $20(64.5)$ & $26.06(6.54-103.84)$ & \\
\hline
\end{tabular}

OR, odds ratio; $\mathrm{CI}$, confidence interval; $\mathrm{MPD}$, main pancreatic duct; $\mathrm{CBD}$, common bile duct; ${ }^{18} \mathrm{~F}-\mathrm{FDG}$ PET $/ \mathrm{CT},{ }^{18} \mathrm{~F}-$ fluorodeoxyglucose positron emission tomography/computed tomography; EUS-FNA, endoscopic ultrasoundguided fine-needle aspiration; LI, labeling index. " Excluding 7 patients (4 in the non-aggressive and 3 in the aggressive groups) who did not undergo ${ }^{18} \mathrm{~F}$-FDG PET/CT. 
Table 4. Multivariate stepwise logistic regression analysis of selected variables.

\begin{tabular}{ccccccc}
\hline \multicolumn{2}{c}{ Variables } & OR (95\% CI) & $p$ Value & $\begin{array}{c}\beta \text { Regression } \\
\text { Coefficients }\end{array}$ & SE & Points \\
\hline Tumor size & $>20 \mathrm{~mm}$ & $9.96(2.05-48.46)$ & 0.004 & 2.30 & 0.80 & 1 \\
\hline Tumor vascularity & Non-hypervascular & $23.23(3.54-152.44)$ & 0.001 & 3.15 & 0.96 & 2 \\
\hline EUS-FNA Ki-67 LI & $\geq 5 \%$ & $6.95(1.16-41.80)$ & 0.034 & 1.94 & 0.92 \\
\hline
\end{tabular}

OR, odds ratio; CI, confidence interval; SE, standard error; EUS-FNA, endoscopic ultrasound-guided fine-needle aspiration; LI, labeling index.

We stratified the patients into three risk groups according to the total points: low-risk ( 0 point), intermediate-risk ( 1 to 2 points), and high-risk ( 3 to 4 points). The proportions of patients with aggressive NF-PanNENs in the low-risk, intermediate-risk, and high-risk groups were $7.5 \%, 50.0 \%, 100 \%$, respectively (Tables 5 and 6 ). There was an increasing trend from the low-risk to the high-risk groups ( $p<0.001$, Cochran-Armitage trend test). The 1-year, 5-year, and 10-year OS rates were different between the three groups $(p<0.001$, Logrank test): all $100 \%$ for the low-risk group; $100 \%, 92.9 \%$, and $84.4 \%$ for the intermediate-risk group; and $56.7 \%, 48.6 \%$, and $24.3 \%$ for the high-risk group, respectively (Figure $2 \mathrm{~A}$ ). Of the 50 patients who underwent R0 resection, the 1-year, 5-year, and 10-year DFS rates were different between the three groups ( $p<0.001$ ): all $100 \%$ for the low-risk group; $100 \%, 71.4 \%$, and $71.4 \%$ for the intermediate-risk group; and $75.0 \%, 0 \%$, and $0 \%$ for the high-risk group, respectively (Figure 2B).

Table 5. The proportions of aggressive NF-PanNENs according to the total points.

\begin{tabular}{ccc}
\hline Total Points & Patients, $\boldsymbol{n}$ & Proportions of Aggressive NF-PanNENs, $\%$ \\
\hline 0 & 40 & $7.5(3 / 40)$ \\
1 & 10 & $40.0(4 / 10)$ \\
2 & 8 & $62.5(5 / 8)$ \\
3 & 6 & $100(6 / 6)$ \\
4 & 13 & $100(13 / 13)$ \\
\hline
\end{tabular}

Table 6. Proportions of aggressive NF-PanNENs according to the risk groups.

\begin{tabular}{cccc}
\hline Risk Groups & Total Points & Patients, $\boldsymbol{n}$ & Proportions of Aggressive NF-PanNENs, $\%$ \\
\hline Low-risk & 0 & 40 & $7.5(3 / 40)$ \\
Intermediate-risk & 1 to 2 & 18 & $50.0(9 / 18)$ \\
High-risk & 3 to 4 & 19 & $100(19 / 19)$ \\
\hline
\end{tabular}

NF-PanNENs, non-functioning pancreatic neuroendocrine neoplasms.

\subsection{The Comparison between the New Scoring System and ENETS TNM Staging System}

We compared the model performance to predict the aggressiveness of NF-PanNENs between the new scoring system and the ENETS TNM staging system. The AUC of the new scoring model and ENETS TNM staging system were 0.92 (95\% CI, 0.85-0.99) with SE of 0.04 and 0.87 (95\% CI, 0.77-0.94) with SE of 0.05, respectively. Although it was not statistically significant, the new model had a higher value of AUC than the ENETS staging system ( $p=0.13$, DeLong test) (Figure 3 ). 
A

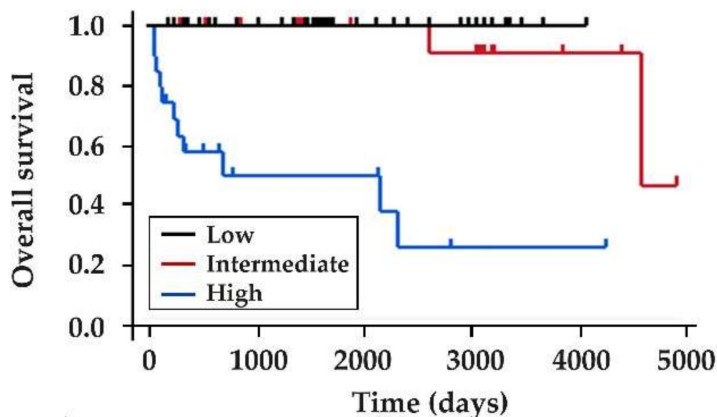

Number at risk

$\begin{array}{lcccccc}\text { Low-risk } & 40 & 31 & 14 & 8 & 1 & 0 \\ \text { Intermediate-risk } & 18 & 15 & 11 & 10 & 3 & 0 \\ \text { High-risk } & 19 & 5 & 5 & 1 & 0 & 0\end{array}$

B

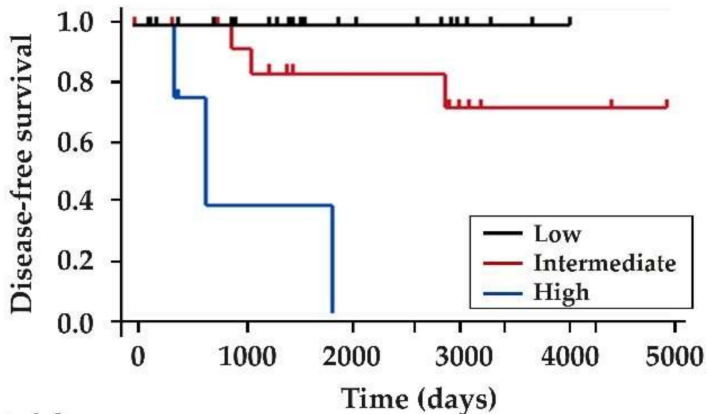

$\begin{array}{lcccccc}\text { Number at risk } & & & & & & \\ \text { Low-risk } & 31 & 23 & 12 & 6 & 1 & 0 \\ \text { Intermediate-risk } & 15 & 12 & 7 & 5 & 2 & 0 \\ \text { High-risk } & 4 & 2 & 0 & 0 & 0 & 0\end{array}$

Figure 2. Kaplan-Meier survival curves of overall and disease-free survival stratified by risk groups. (A) Overall survival of all enrolled patients and (B) disease-free survival of the patients who underwent $\mathrm{R} 0$ resection were different between the three groups (both for $p<0.001$ ).

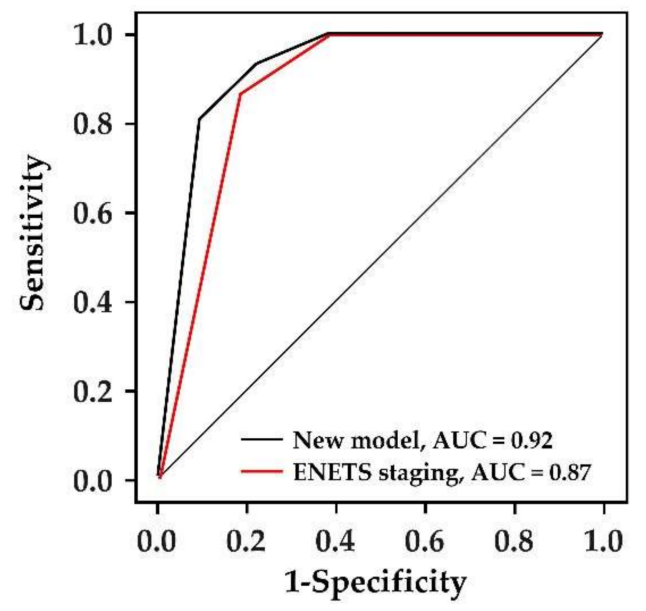

Figure 3. Receiver operating characteristic curve for predicting aggressiveness of non-functioning pancreatic neuroendocrine neoplasms. Although it was not statistically significant, the new model had a higher value of area under the curve than the ENETS staging system $(p=0.13)$.

\section{Discussion}

In this study, we developed a new scoring system useful for treatment decisions at initial diagnosis in patients with NF-PanNENs. We first identified the predictive factors for the aggressiveness of NF-PanNENs, which can be evaluated preoperatively without resected specimens. Two imaging factors on CE-CT (tumor size $>20 \mathrm{~mm}$ and tumor nonhypervascularity) and one pathological factor (Ki-67 LI $\geq 5 \%$ on EUS-FNA specimens) were identified as independent factors associated with the aggressiveness of NF-PanNENs. We then developed a scoring system using these three identified factors. These factors were not included in our definition of aggressive NF-PanNENs. This new scoring system had a reliable performance and could stratify the long-term prognosis and the postoperative recurrence. The strength of this new scoring system is that it can be evaluated before treatment, because the resected specimens were not required for the evaluation. This scoring system may provide useful information for treatment decisions, such as surgery and surveillance, and predicting the prognosis in patients with NF-PanNENs.

We identified tumor size as one of the predictive factors. This agrees with the previous studies showing that tumor size was associated with tumor grade, prognosis, and postoperative recurrence [10-12]. Although $20 \mathrm{~mm}$ is a previously reported 
cut-off value for distinguishing malignancy [16,17], highly malignant lesions might exist in tumors $\leq 20 \mathrm{~mm}[19,31]$. Millis et al. [19] reported that 38\% (24/66) of sporadic NFPanNENs with tumors $\leq 20 \mathrm{~mm}$ had malignant features such as vascular invasion, lymph node, and distant metastases. In a multicenter study of 210 resected NF-PanNENs cases with tumors $\leq 20 \mathrm{~mm}$, Sallinen et al. [31] reported that $10.6 \%$ of cases had lymph node metastases and 19\% had G2-3 tumors. In this study, 9/50 (18\%) patients whose tumor size was $\leq 20 \mathrm{~mm}$ were classified into the aggressive group. Collectively, tumor size alone is insufficient for estimating the aggressiveness of NF-PanNENs.

In addition to tumor size, we identified the non-hypervascularity of tumors as an independent predictive factor. Tumor non-hypervascularity had the highest $\beta$ regression coefficient among the three identified factors and was given the highest point in the scoring system. Our result supports the previous studies showing the association of non-vascularity with tumor grade [30,48]. Zamboni et al. [48] reviewed 154 patients with NF-PanNENs and reported that arterial vascularization differentiated tumor grade, with G1 tumors being more hypervascular and G3 tumors being more non-hypervascular. Yamada et al. [30] analyzed 37 NF-PanNENs of G1 and G2 with preoperative multiphase CT and reported that $\mathrm{HU}$ value in G1 tumors was higher than that of G2 tumors. They also reported the AUC of HU value was higher than that of tumor size. On the other hand, in a multicenter retrospective study of 158 patients with surgically resected NF-PanNENs $\leq 20 \mathrm{~mm}$ [49], hyperenhancement in the arteria phase was not associated with metastases or recurrences. However, this study included only small lesions, and $87 \%$ of patients were diagnosed by surgical specimens, indicating that the patients with high malignant potential such as unrespectable cases might have been excluded. In our study, 56.5\% (13/23) of nonhypervascular NF-PanNENs had distant metastases at initial diagnosis (data not shown). Non-hyperenhancement suggests aggressive lesions.

Recently, there is accumulating evidence that EUS is useful for predicting the aggressiveness of PanNENs [9,41,50]. For example, Crinó et al. [50] showed irregular margins and tumor size $>20 \mathrm{~mm}$ on EUS were associated with malignancy and aggressiveness of PanNENs. Ishikawa et al. [41] showed hypo-enhancement on contrast-enhanced harmonic EUS (CE-EUS) was an indicator of aggressive PanNENs. Compared to CE-CT, CE-EUS has advantages such as a higher detection rate of small lesions and the ability to use contrast media even in patients with renal failure. Further studies are needed to clarify whether CE-EUS is superior to CE-CT for predicting malignancy, or whether a combination of the two modalities increases diagnostic abilities.

In general, tumor grade based on Ki-67 LI strongly reflects the malignant potential of NF-PanNENs [16,36], and Ki-67 LI on EUS-FNA specimens has been reported as a useful prognostic factor. Boutsen et al. [34] reported that tumor grade on EUS-FNA specimens was associated with OS in 101 patients with NF-PanNENs. Cui et al. [35] reported similar results in 37 resected cases. However, it is known that Ki-67 LI in EUS-FNA specimens is often inconsistent with that obtained on surgical specimens [7,51]. A pooled analysis showed a grade concordance rate of 77.5\% between EUS-FNA and surgical specimens [7]. Importantly, previous studies showed a better tumor grade concordance rate between EUS-FNA and surgical specimens in smaller PanNENs [52,53]. Paiella et al. [53] reported that correlation of Ki-67 LI between EUS-FNA and surgical specimens was strong in PanNENs $\leq 20 \mathrm{~mm}$, whereas it was moderate in PanNENs $>20 \mathrm{~mm}$. A EUS-guided fine needle biopsy (EUSFNB) sampling procedure, using new core biopsy needles, has been developed to improve the sample quantity and quality [54]. A meta-analysis of 11 randomized controlled trials revealed that EUS-FNB had a better specimen adequacy, higher diagnostic accuracy, and a fewer number of needle-passes than EUS-FNA for sampling pancreatic masses [54]. This might also be the case for evaluation of the Ki-67 LI in PanNENs. Crinó et al. [55] reported that EUS-FNB specimens had a stronger correlation with surgical specimens for Ki-67 LI than EUS-FNA. They also showed that EUS-FNB specimens had better assessment feasibility of Ki-67 LI than EUS-FNA specimens in PanNETs $\leq 20 \mathrm{~mm}$. Ki-67 LI assessment by EUS-FNA/B is essential for preoperative prediction for the aggressiveness of NF- 
PanNENs, and the widespread use of EUS-FNB would increase the reliability of the present scoring system, especially for lesions $\leq 20 \mathrm{~mm}$.

Although previous studies have developed scoring models for predicting the malignant potential of NF-PanNENs, most of them could be evaluated only after surgery [24-27]. Fisher et al. [56] reported a risk score focusing on preoperative factors, including chromogranin A, tumor grade, tumor size, and presence of metastasis. However, they reviewed patients with curative resection, indicating that the patients with high malignancy were not included. In addition, tumor grade was evaluated based on final pathological report, therefore their model could not be used for preoperative treatment decisions. Primavesi et al. [57] developed a scoring model using only preoperative factors, including C-reactive protein, presence of metastasis, and tumor size, which were associated with the prognosis of NF-PanNENs patients. However, their study included only patients with curative resection, and postoperative factors, such as tumor grade and lymph node metastasis based on surgical specimens, were included. Unlike these previous studies, we employed predictable factors available preoperatively, and we analyzed all of the resected, unresectable, and surveillance cases. Our scoring system had a high discrimination ability (AUC, 0.92). The assessment of tumor vascularity on CE-CT and pathological evaluation of Ki-67 LI on EUS-FNA specimens, which are not included in the ENETS TNM staging system, may contribute to the increased discrimination ability.

The usefulness of less-invasive EUS-guided radiofrequency ablation (EUS-RFA) has been recently reported [58]. EUS-RFA might be a treatment option for patients in the low-risk group, particularly for those with high surgical risk. EUS-RFA is not basically indicated for patients in the intermediate-risk group because 33.3\% (6/18) had lymph node metastasis (data not shown). Therefore, for patients in the intermediate- and high-risk groups, surgery should be selected if the patient can tolerate it. Neoadjuvant chemotherapy might be considered in the future, because all patients with $\mathrm{R} 0$ resection in these groups showed postoperative recurrence within 5 years.

This study has several limitations. First, the sample size is relatively small and external validation is lacking, which may lead to overestimation of the new scoring system. Although events per variable in this study $(31 / 3=10.3)$ met the recommended amount (over 10) to fit a prediction model using logistic regression [59], the small sample size led to a wide $95 \%$ CI in each variable. Second, this study was a single-center and retrospective study. Third, this scoring model requires lesions detectable on CE-CT and sufficient samples on EUS-FNA specimens. Due to this limitation, we excluded two patients who were undetectable on CE-CT and three patients with insufficient samples by EUS-FNA. Recent studies have demonstrated that NF-PanNENs $\leq 10 \mathrm{~mm}$ had very low malignant potential $[15,49]$. The scoring system might require further stratification based on tumor size $\leq 10 \mathrm{~mm}$, which could not be performed due to the small sample size in this study.

\section{Conclusions}

We here developed a new scoring system for predicting the aggressiveness of NFPanNENs using the three factors (tumor size, tumor non-hypervascularity on CE-CT, and Ki-67 LI on EUS-FNA specimens) that can be assessed preoperatively. This model may be useful for treatment decisions as well as for prognosis prediction at initial diagnosis. Further multi-center, prospective studies are warranted to validate this scoring system in larger cohorts.

Author Contributions: Conceptualization, T.T. and A.M.; methodology, T.T., W.H., and A.M.; formal analysis, T.T., W.H., Y.O. and A.M.; investigation, T.T., K.K. (Kazuhiro Kikuta), S.H., K.K. (Kiyoshi Kume), S.M., N.Y., Y.T., R.M., M.I., F.K., A.S., H.H., K.N. and M.U.; data curation, T.T.; writingoriginal draft preparation, T.T. and A.M.; writing—review and editing, A.M.; visualization, T.T.; supervision, A.M.; project administration, A.M.; funding acquisition, K.K. (Kazuhiro Kikuta) and A.M. All authors have read and agreed to the published version of the manuscript. 
Funding: This work was supported in part by JSPS KAKENHI, Grant Number 20K21593 (to A.M.) and a Grant-in-Aid from KUROKAWA CANCER RESEARCH FOUNDATION (to K.K. (Kazuhiro Kikuta)).

Institutional Review Board Statement: The study was conducted according to the guidelines of the Declaration of Helsinki and approved by the Ethics Committee of Tohoku University Graduate School of Medicine (article number: 2019-1-919 \& 2019-1-920).

Informed Consent Statement: Patient consent was waived due to the retrospective nature of this study.

Data Availability Statement: The data used during the current study are available from the corresponding author upon reasonable request.

Conflicts of Interest: The authors declare no conflict of interest.

\section{References}

1. Falconi, M.; Eriksson, B.; Kaltsas, G.; Bartsch, D.K.; Capdevila, J.; Caplin, M.; Kos-Kudla, B.; Kwekkeboom, D.; Rindi, G.; Kloppel, G.; et al. ENETS consensus guidelines update for the management of patients with functional pancreatic neuroendocrine tumors and non-functional pancreatic neuroendocrine tumors. Neuroendocrinology 2016, 103, 153-171. [CrossRef] [PubMed]

2. Das, S.; Dasari, A. Epidemiology, incidence, and prevalence of neuroendocrine neoplasms: Are there global differences? Curr. Oncol. Rep. 2021, 23, 43. [CrossRef] [PubMed]

3. Wang, J.; Liu, J.; He, C.; Sun, T.; Yan, Y.; Che, G.; Li, X.; Sun, H.; Ma, H. Trends in incidence and survival of patients with pancreatic neuroendocrine neoplasm, 1987-2016. J. Oncol. 2021, 2021, 11. [CrossRef]

4. Kuo, E.J.; Salem, R.R. Population-level analysis of pancreatic neuroendocrine tumors $2 \mathrm{~cm}$ or less in size. Ann. Surg. Oncol. 2013, 20, 2815-2821. [CrossRef]

5. Ji, S.; Liu, M.; Xia, H.; Ye, Z.; Xu, X.; Yu, X.; Zhuo, Q. Management of small nonfunctioning pancreatic neuroendocrine tumors: An analysis of the US surveillance, epidemiology, and end results database. Pancreas 2021, 50, e8-e10. [CrossRef] [PubMed]

6. Stensbøl, A.B.; Krogh, J.; Holmager, P.; Klose, M.; Oturai, P.; Kjaer, A.; Hansen, C.P.; Federspiel, B.; Langer, S.W.; Knigge, U.; et al. Incidence, clinical presentation and trends in indication for diagnostic work-up of small intestinal and pancreatic neuroendocrine tumors. Diagnostics 2021, 11, 2030. [CrossRef]

7. Ishii, T.; Katanuma, A.; Toyonaga, H.; Chikugo, K.; Nasuno, H.; Kin, T.; Hayashi, T.; Takahashi, K. Role of endoscopic ultrasound in the diagnosis of pancreatic neuroendocrine neoplasms. Diagnostics 2021, 11, 316. [CrossRef] [PubMed]

8. Grimelius, L.; Hultquist, G.T.; Stenkvist, B. Cytological differentiation of asymptomatic pancreatic islet cell tumours in autopsy material. Virchows Arch. A Pathol. Anat. Histol. 1975, 365, 275-288. [CrossRef]

9. Kimura, W.; Kuroda, A.; Morioka, Y. Clinical pathology of endocrine tumors of the pancreas. Analysis of autopsy cases. Dig. Dis. Sci. 1991, 36, 933-942. [CrossRef]

10. Bettini, R.; Partelli, S.; Boninsegna, L.; Capelli, P.; Crippa, S.; Pederzoli, P.; Scarpa, A.; Falconi, M. Tumor size correlates with malignancy in nonfunctioning pancreatic endocrine tumor. Surgery 2011, 150, 75-82. [CrossRef]

11. Slagter, A.E.; Ryder, D.; Chakrabarty, B.; Lamarca, A.; Hubner, R.A.; Mansoor, W.; O’Reilly, D.A.; Fulford, P.E.; Klümpen, H.J.; Valle, J.W.; et al. Prognostic factors for disease relapse in patients with neuroendocrine tumours who underwent curative surgery. Surg. Oncol. 2016, 25, 223-228. [CrossRef] [PubMed]

12. Bu, J.; Youn, S.; Kwon, W.; Jang, K.T.; Han, S.; Han, S.; You, Y.; Heo, J.S.; Choi, S.H.; Choi, D.W. Prognostic factors of nonfunctioning pancreatic neuroendocrine tumor revisited: The value of WHO 2010 classification. Ann. Hepatobiliary Pancreat Surg 2018, 22, 66-74. [CrossRef] [PubMed]

13. Gaujoux, S.; Partelli, S.; Maire, F.; D’Onofrio, M.; Larroque, B.; Tamburrino, D.; Sauvanet, A.; Falconi, M.; Ruszniewski, P. Observational study of natural history of small sporadic nonfunctioning pancreatic neuroendocrine tumors. J. Clin. Endocrinol. Metab. 2013, 98, 4784-4789. [CrossRef] [PubMed]

14. Rosenberg, A.M.; Friedmann, P.; del Rivero, J.; Libutti, S.K.; Laird, A.M. Resection versus expectant management of small incidentally discovered nonfunctional pancreatic neuroendocrine tumors. Surgery 2016, 159, 302-309. [CrossRef] [PubMed]

15. Kurita, Y.; Hara, K.; Kuwahara, T.; Mizuno, N.; Okuno, N.; Haba, S.; Okuno, M.; Natsume, S.; Senda, Y.; Kubota, K.; et al. Comparison of prognosis between observation and surgical resection groups with small sporadic non-functional pancreatic neuroendocrine neoplasms without distant metastasis. J. Gastroenterol. 2020, 55, 543-552. [CrossRef]

16. Partelli, S.; Bartsch, D.K.; Capdevila, J.; Chen, J.; Knigge, U.; Niederle, B.; Nieveen van Dijkum, E.J.M.; Pape, U.F.; Pascher, A.; Ramage, J.; et al. ENETS consensus guidelines for standard of care in neuroendocrine tumours: Surgery for small intestinal and pancreatic neuroendocrine tumours. Neuroendocrinology 2017, 105, 255-265. [CrossRef] [PubMed]

17. Shah, M.H.; Goldner, W.S.; Benson, A.B.; Bergsland, E.; Blaszkowsky, L.S.; Brock, P.; Chan, J.; Das, S.; Dickson, P.V.; Fanta, P.; et al. Neuroendocrine and Adrenal Tumors, Version 4.2021, NCCN Clinical Practice Guidelines in Oncology. Available online: https:/ / www.nccn.org/guidelines/guidelines-detail?category=1\&id=1448 (accessed on 25 December 2021).

18. Sharpe, S.M.; In, H.; Winchester, D.J.; Talamonti, M.S.; Baker, M.S. Surgical resection provides an overall survival benefit for patients with small pancreatic neuroendocrine tumors. J. Gastrointest. Surg. 2015, 19, 117-123. [CrossRef] 
19. Mills, L.; Drymousis, P.; Vashist, Y.; Burdelski, C.; Prachalias, A.; Srinivasan, P.; Menon, K.; Cotoi, C.; Khan, S.; Cave, J.; et al. Tumour diameter is not reliable for management of non-secreting pancreatic neuroendocrine tumours. Endocr. Connect. 2017, 6, 876-885. [CrossRef]

20. Bilimoria, K.Y.; Talamonti, M.S.; Tomlinson, J.S.; Stewart, A.K.; Winchester, D.P.; Ko, C.Y.; Bentrem, D.J. Prognostic score predicting survival after resection of pancreatic neuroendocrine tumors: Analysis of 3851 patients. Ann. Surg. 2008, 247, 490-500. [CrossRef]

21. Cheng, Y.; Zhan, H.; Wang, L.; Xu, J.; Zhang, G.; Zhang, Z.; Hu, S. Analysis of 100 consecutive cases of resectable pancreatic neuroendocrine neoplasms: Clinicopathological characteristics and long-term outcomes. Front. Med. 2016, 10, 444-450. [CrossRef]

22. Zhou, B.; Duan, J.; Yan, S.; Zhou, J.; Zheng, S. Prognostic factors of long-term outcome in surgically resectable pancreatic neuroendocrine tumors: A 12-year experience from a single center. Oncol. Lett. 2017, 13, 1157-1164. [CrossRef] [PubMed]

23. Gao, Y.; Gao, H.; Wang, G.; Yin, L.; Xu, W.; Peng, Y.; Wu, J.; Jiang, K.; Miao, Y. A meta-analysis of prognostic factor of pancreatic neuroendocrine neoplasms. Sci. Rep. 2018, 8, 7271. [CrossRef] [PubMed]

24. Genç, C.G.; Jilesen, A.P.; Partelli, S.; Falconi, M.; Muffatti, F.; van Kemenade, F.J.; van Eeden, S.; Verheij, J.; van Dieren, S.; van Eijck, C.H.J.; et al. A new scoring system to predict recurrent disease in grade 1 and 2 nonfunctional pancreatic neuroendocrine tumors. Ann. Surg. 2018, 267, 1148-1154. [CrossRef] [PubMed]

25. Zaidi, M.Y.; Lopez-Aguiar, A.G.; Switchenko, J.M.; Lipscomb, J.; Andreasi, V.; Partelli, S.; Gamboa, A.C.; Lee, R.M.; Poultsides, G.A.; Dillhoff, M.; et al. A novel validated recurrence risk score to guide a pragmatic surveillance strategy after resection of pancreatic neuroendocrine tumors: An international study of 1006 patients. Ann. Surg. 2019, 270, 422-433. [CrossRef]

26. Ge, L.; Li, H.; Dong, L.; Shang, G.; Wang, W.; Li, Y.; Qi, L.; Zhao, J.; Peng, D.; Tong, G. Nomogram for predicting survival of patients with metastatic nonfunctioning pancreatic neuroendocrine tumors: A SEER based study. Medicine 2021, 100, e26347. [CrossRef]

27. Wang, W.Q.; Zhang, W.H.; Gao, H.L.; Huang, D.; Xu, H.X.; Li, S.; Li, T.J.; Xu, S.S.; Li, H.; Long, J.; et al. A novel risk factor panel predicts early recurrence in resected pancreatic neuroendocrine tumors. J. Gastroenterol. 2021, 56, 395-405. [CrossRef]

28. Canellas, R.; Burk, K.S.; Parakh, A.; Sahani, D.V. Prediction of pancreatic neuroendocrine tumor grade based on CT features and texture analysis. AJR Am. J. Roentgenol. 2018, 210, 341-346. [CrossRef]

29. Nanno, Y.; Matsumoto, I.; Zen, Y.; Otani, K.; Uemura, J.; Toyama, H.; Asari, S.; Goto, T.; Ajiki, T.; Okano, K.; et al. Pancreatic duct involvement in well-differentiated neuroendocrine tumors is an independent poor prognostic factor. Ann. Surg. Oncol. 2017, 24, 1127-1133. [CrossRef]

30. Yamada, S.; Fujii, T.; Suzuki, K.; Inokawa, Y.; Kanda, M.; Nakayama, G.; Sugimoto, H.; Koike, M.; Nomoto, S.; Fujiwara, M.; et al. Preoperative identification of a prognostic factor for pancreatic neuroendocrine tumors using multiphase contrast-enhanced computed tomography. Pancreas 2016, 45, 198-203. [CrossRef]

31. Sallinen, V.J.; le Large, T.Y.S.; Tieftrunk, E.; Galeev, S.; Kovalenko, Z.; Haugvik, S.P.; Antila, A.; Franklin, O.; Martinez-Moneo, E.; Robinson, S.M.; et al. Prognosis of sporadic resected small $(\leq 2 \mathrm{~cm})$ nonfunctional pancreatic neuroendocrine tumors-A multi-institutional study. HPB 2018, 20, 251-259. [CrossRef]

32. Karmazanovsky, G.; Belousova, E.; Schima, W.; Glotov, A.; Kalinin, D.; Kriger, A. Nonhypervascular pancreatic neuroendocrine tumors: Spectrum of MDCT imaging findings and differentiation from pancreatic ductal adenocarcinoma. Eur. J. Radiol. 2019, 110, 66-73. [CrossRef]

33. Binderup, T.; Knigge, U.; Johnbeck, C.B.; Loft, A.; Berthelsen, A.K.; Oturai, P.; Mortensen, J.; Federspiel, B.; Langer, S.W.; Kjaer, A. ${ }^{18}$ F-FDG PET is superior to WHO grading as a prognostic tool in neuroendocrine neoplasms and useful in guiding PRRT: A prospective 10-year follow-up study. J. Nucl. Med. 2021, 62, 808-815. [CrossRef] [PubMed]

34. Boutsen, L.; Jouret-Mourin, A.; Borbath, I.; van Maanen, A.; Weynand, B. Accuracy of pancreatic neuroendocrine tumour grading by endoscopic ultrasound-guided fine needle aspiration: Analysis of a large cohort and perspectives for improvement. Neuroendocrinology 2018, 106, 158-166. [CrossRef] [PubMed]

35. Cui, Y.; Khanna, L.G.; Saqi, A.; Crapanzano, J.P.; Mitchell, J.M.; Sethi, A.; Gonda, T.A.; Kluger, M.D.; Schrope, B.A.; Allendorf, J.; et al. The role of endoscopic ultrasound-guided ki67 in the management of non-functioning pancreatic neuroendocrine tumors. Clin. Endosc. 2020, 53, 213-220. [CrossRef]

36. Kloppel, G.; la Rosa, S. Ki67 labeling index: Assessment and prognostic role in gastroenteropancreatic neuroendocrine neoplasms. Virchows Arch. 2018, 472, 341-349. [CrossRef] [PubMed]

37. Genç, C.G.; Falconi, M.; Partelli, S.; Muffatti, F.; van Eeden, S.; Doglioni, C.; Klümpen, H.J.; van Eijck, C.H.J.; Nieveen van Dijkum, E.J.M. Recurrence of pancreatic neuroendocrine tumors and survival predicted by Ki67. Ann. Surg. Oncol. 2018, 25, $2467-2474$. [CrossRef]

38. Aysal, A.; Agalar, C.; Egeli, T.; Unek, T.; Oztop, I.; Obuz, F.; Sagol, O. Reconsideration of clinicopathologic prognostic factors in pancreatic neuroendocrine tumors for better determination of adverse prognosis. Endocr. Pathol. 2021, 32, 461-472. [CrossRef]

39. Rindi, G.; Klöppel, G.; Alhman, H.; Caplin, M.; Couvelard, A.; de Herder, W.W.; Erikssson, B.; Falchetti, A.; Falconi, M.; Komminoth, P.; et al. TNM staging of foregut (neuro)endocrine tumors: A consensus proposal including a grading system. Virchows Arch. 2006, 449, 395-401. [CrossRef]

40. Ricci, C.; Taffurelli, G.; Campana, D.; Ambrosini, V.; Pacilio, C.A.; Pagano, N.; Santini, D.; Brighi, N.; Minni, F.; Casadei, R. Is surgery the best treatment for sporadic small $(\leq 2 \mathrm{~cm})$ non-functioning pancreatic neuroendocrine tumours? A single centre experience. Pancreatology 2017, 17, 471-477. [CrossRef] 
41. Ishikawa, R.; Kamata, K.; Hara, A.; Tanaka, H.; Okamoto, A.; Yamazaki, T.; Nakai, A.; Omoto, S.; Minaga, K.; Yamao, K.; et al. Utility of contrast-enhanced harmonic endoscopic ultrasonography for predicting the prognosis of pancreatic neuroendocrine neoplasms. Dig. Endosc. 2021, 33, 829-839. [CrossRef]

42. Belousova, E.; Karmazanovsky, G.; Kriger, A.; Kalinin, D.; Mannelli, L.; Glotov, A.; Karelskaya, N.; Paklina, O.; Kaldarov, A. Contrast-enhanced MDCT in patients with pancreatic neuroendocrine tumours: Correlation with histological findings and diagnostic performance in differentiation between tumour grades. Clin. Radiol. 2017, 72, 150-158. [CrossRef] [PubMed]

43. Eisenhauer, E.A.; Therasse, P.; Bogaerts, J.; Schwartz, L.H.; Sargent, D.; Ford, R.; Dancey, J.; Arbuck, S.; Gwyther, S.; Mooney, M.; et al. New response evaluation criteria in solid tumours: Revised RECIST guideline (Version 1.1). Eur. J. Cancer 2009, 45, 228-247. [CrossRef]

44. Hatta, W.; Gotoda, T.; Oyama, T.; Kawata, N.; Takahashi, A.; Yoshifuku, Y.; Hoteya, S.; Nakagawa, M.; Hirano, M.; Esaki, M.; et al. A scoring system to stratify curability after endoscopic submucosal dissection for early gastric cancer: "eCura System". Am. J. Gastroenterol. 2017, 112, 874-881. [CrossRef] [PubMed]

45. Matsuhashi, T.; Hatta, W.; Hikichi, T.; Fukuda, S.; Mikami, T.; Tatsuta, T.; Nakamura, J.; Abe, Y.; Onozato, Y.; Ogata, Y.; et al. A simple prediction score for in-hospital mortality in patients with nonvariceal upper gastrointestinal bleeding. J. Gastroenterol. 2021, 56, 758-768. [CrossRef]

46. Mehta, H.B.; Mehta, V.; Girman, C.J.; Adhikari, D.; Johnson, M.L. Regression coefficient-based scoring system should be used to assign weights to the risk index. J. Clin. Epidemiol. 2016, 79, 22-28. [CrossRef] [PubMed]

47. Delong, E.R.; Delong, D.M.; Clarke-Pearson, D.L. Comparing the areas under two or more correlated receiver operating characteristic curves: A nonparametric approach. Biometrics 1988, 44, 837-845. [CrossRef] [PubMed]

48. Zamboni, G.A.; Ambrosetti, M.C.; Zivelonghi, C.; Lombardo, F.; Butturini, G.; Cingarlini, S.; Capelli, P.; Pozzi Mucelli, R. Solid non-functioning endocrine tumors of the pancreas: Correlating computed tomography and pathology. HPB 2017, 19, 986-991. [CrossRef]

49. Paik, W.H.; Lee, H.S.; Lee, K.J.; Jang, S.I.; Lee, W.J.; Hwang, J.H.; Cho, C.M.; Park, C.H.; Han, J.; Woo, S.M.; et al. Malignant potential of small pancreatic neuroendocrine neoplasm and its risk factors: A multicenter nationwide study. Pancreatology 2021, 21, 208-214. [CrossRef]

50. Crinó, S.F.; Brandolese, A.; Vieceli, F.; Paiella, S.; Conti Bellocchi, M.C.; Manfrin, E.; Bernardoni, L.; Sina, S.; D’Onofrio, M.; Marchegiani, G.; et al. Endoscopic ultrasound features associated with malignancy and aggressiveness of nonhypovascular solid pancreatic lesions: Results from a prospective observational study. Ultraschall Med. 2021, 42, 167-177. [CrossRef]

51. Hwang, H.S.; Kim, Y.; An, S.; Kim, S.J.; Kim, J.Y.; Kim, S.Y.; Hwang, D.W.; Park, D.H.; Lee, S.S.; Kim, S.C.; et al. Grading by the $\mathrm{Ki}-67$ labeling index of endoscopic ultrasound-guided fine needle aspiration biopsy specimens of pancreatic neuroendocrine tumors can be underestimated. Pancreas 2018, 47, 1296-1303. [CrossRef]

52. Unno, J.; Kanno, A.; Masamune, A.; Kasajima, A.; Fujishima, F.; Ishida, K.; Hamada, S.; Kume, K.; Kikuta, K.; Hirota, M.; et al The usefulness of endoscopic ultrasound-guided fine-needle aspiration for the diagnosis of pancreatic neuroendocrine tumors based on the world health organization classification. Scand. J. Gastroenterol. 2014, 49, 1367-1374. [CrossRef]

53. Paiella, S.; Landoni, L.; Rota, R.; Valenti, M.; Elio, G.; Crinò, S.F.; Manfrin, E.; Parisi, A.; Cingarlini, S.; D’Onofrio, M.; et al Endoscopic ultrasound-guided fine-needle aspiration for the diagnosis and grading of pancreatic neuroendocrine tumors: A Retrospective analysis of 110 cases. Endoscopy 2020, 52, 988-994. [CrossRef] [PubMed]

54. Li, H.; Li, W.; Zhou, Q.Y.; Fan, B. Fine needle biopsy is superior to fine needle aspiration in endoscopic ultrasound guided sampling of pancreatic masses: A meta-analysis of randomized controlled trials. Medicine 2018, 97, e0207. [CrossRef]

55. Crinò, S.F.; Ammendola, S.; Meneghetti, A.; Bernardoni, L.; Conti Bellocchi, M.C.; Gabbrielli, A.; Landoni, L.; Paiella, S.; Pin, F.; Parisi, A.; et al. Comparison between EUS-guided fine-needle aspiration cytology and EUS-guided fine-needle biopsy histology for the evaluation of pancreatic neuroendocrine tumors. Pancreatology 2021, 21, 443-450. [CrossRef] [PubMed]

56. Fisher, A.V.; Lopez-Aguiar, A.G.; Rendell, V.R.; Pokrzywa, C.; Rocha, F.G.; Kanji, Z.S.; Poultsides, G.A.; Makris, E.A.; Dillhoff, M.E.; Beal, E.W.; et al. Predictive value of chromogranin a and a pre-operative risk score to predict recurrence after resection of pancreatic neuroendocrine tumors. J. Gastrointest. Surg. 2019, 23, 651-658. [CrossRef] [PubMed]

57. Primavesi, F.; Andreasi, V.; Hoogwater, F.J.H.; Partelli, S.; Wiese, D.; Heidsma, C.; Cardini, B.; Klieser, E.; Marsoner, K.; Fröschl, U.; et al. A preoperative clinical risk score including c-reactive protein predicts histological tumor characteristics and patient survival after surgery for sporadic non-functional pancreatic neuroendocrine neoplasms: An international multicenter cohort study. Cancers 2020, 12, 1235. [CrossRef] [PubMed]

58. Larghi, A.; Rizzatti, G.; Rimbaş, M.; Crino, S.F.; Gasbarrini, A.; Costamagna, G. EUS-guided radiofrequency ablation as an alternative to surgery for pancreatic neuroendocrine neoplasms: Who should we treat? Endosc. Ultrasound 2019, 8, 220-226. [CrossRef]

59. Peduzzi, P.; Concato, J.; Kemper, E.; Holford, T.R.; Feinstein, A.R. A Simulation study of the number of events per variable in logistic regression analysis. J. Clin. Epidemiol. 1996, 49, 1373-1379. [CrossRef] 